\title{
Harnessing Genetic Diversity of Wild Gene Pools to Enhance Wheat Crop Production and Sustainability: Challenges and Opportunities
}

\author{
Carla Ceoloni *, Ljiljana Kuzmanović, Roberto Ruggeri, Francesco Rossini, Paola Forte, \\ Alessia Cuccurullo and Alessandra Bitti \\ Department of Agricultural and Forest Sciences (DAFNE), University of Tuscia, 01100 Viterbo, Italy; \\ ljiljanakuzmanovic@gmail.com (L.K.); r.ruggeri@unitus.it (R.R.); rossini@unitus.it (F.R.); \\ pforte64@gmail.com (P.F.); alessia2105@gmail.com (A.C.); bittia@unitus.it (A.B.) \\ * Correspondence: ceoloni@unitus.it; Tel.: +39-761-357-202
}

Received: 24 October 2017; Accepted: 26 November 2017; Published: 1 December 2017

\begin{abstract}
Wild species are extremely rich resources of useful genes not available in the cultivated gene pool. For species providing staple food to mankind, such as the cultivated Triticum species, including hexaploid bread wheat (Triticum aestivum, 6x) and tetraploid durum wheat (T. durum, 4x), widening the genetic base is a priority and primary target to cope with the many challenges that the crop has to face. These include recent climate changes, as well as actual and projected demographic growth, contrasting with reduction of arable land and water reserves. All of these environmental and societal modifications pose major constraints to the required production increase in the wheat crop. A sustainable approach to address this task implies resorting to non-conventional breeding strategies, such as "chromosome engineering". This is based on cytogenetic methodologies, which ultimately allow for the incorporation into wheat chromosomes of targeted, and ideally small, chromosomal segments from the genome of wild relatives, containing the gene(s) of interest. Chromosome engineering has been successfully applied to introduce into wheat genes/QTL for resistance to biotic and abiotic stresses, quality attributes, and even yield-related traits. In recent years, a substantial upsurge in effective alien gene exploitation for wheat improvement has come from modern technologies, including use of molecular markers, molecular cytogenetic techniques, and sequencing, which have greatly expanded our knowledge and ability to finely manipulate wheat and alien genomes. Examples will be provided of various types of stable introgressions, including pyramiding of different alien genes/QTL, into the background of bread and durum wheat genotypes, representing valuable materials for both species to respond to the needed novelty in current and future breeding programs. Challenging contexts, such as that inherent to the $4 \mathrm{x}$ nature of durum wheat when compared to $6 \mathrm{x}$ bread wheat, or created by presence of alien genes affecting segregation of wheat-alien recombinant chromosomes, will also be illustrated.
\end{abstract}

Keywords: Triticum; crop wild relatives; alien gene transfer; alien gene pyramiding; chromosome engineering; segregation distortion; new plant breeding techniques

\section{Global Crop Demand: the Need for New Strategies}

In recent years, scientists and experts from different fields are increasingly focusing on the challenging and threatening projection that in the next 50 years we will need to produce as much food as has been consumed over our entire human history. The growing population will cause exponentially rising demand, and a warming climate, water scarcity, and arable land shrinkage will make the challenge more difficult. 
With a world acreage of over 220 million hectares in 2016-2017 [1], wheat covers more of the Earth than any other crop, and, among the major staple cereal crops, it is the only one that is adapted to low temperatures, hence can be grown during the cool season. This gives it a unique position in many different crop rotations across the globe with rice, cotton, soybean, and corn. Because of its adaptability, ease of grain storage, and ease of converting grain into flour, wheat is a major global diet component, providing more than $20 \%$ of calories for human consumption, a figure that jumps to $50 \%$ in places like Africa and parts of Asia.

The "Green revolutions" of the 20th century [2,3] had dramatic results on increasing food production: as to wheat, India alone doubled its harvest from 1965 to 1972, and the worldwide wheat production systems have been, in general, highly successful in increasing yield with respect to that existing at the beginning of the century [4]. The high rate of yield gains, which was particularly prominent in the second half of the century, was consistent for both the bread wheat [4] and the durum wheat [5] crop. However, on one hand, projections by 2050 forecast a considerable gap between demand and supply, particularly if climate-change-induced stresses are considered [6,7]; on the other hand, in a sustainable perspective, pathways that mimic past trends for increasing yield to meet global food demand are no longer practicable, as they would imply severe effects on the environment [8]. Instead, trajectories of global agricultural development that are directed to greater achievement of the technology improvement and technology transfer to less-developed and lower-yielding countries, are expected to enable the preservation of global biodiversity and to minimize major environmental impacts of agriculture, such as those due to greenhouse gas emissions and nitrogen use [8].

In fact, for wheat and all of the major cereal crops, yield increases have been plateauing in recent years, as if yield potential had approached its ceiling $[7,8]$. However, since depressed rates of progress do not seem to be majorly due to biological limits in the system [7], space for effectual interventions to counter yield stagnation does exist. Recent comprehensive analyses suggest that, as in the past 20-30 years, future yield progress will depend more on breeding than on new developments in crop agronomy [7,9]. A large genetic basis is pre-requisite for successful breeding; yet, current breeding materials contain only a fraction of the useful genetic variation available within crop related gene pools, which is perhaps comparable to the visible portion of an iceberg. As for other crops, wheat relatives, particularly wild Triticeae species, provide a vast reservoir for most, if not all, agronomically important traits [10,11], for which a unique array of cytogenetic materials have in many cases allowed for the identification of the carrier chromosome or chromosome arm. From such pre-breeding stocks, including addition and substitution lines of single alien chromosomes into the wheat genome, the most successful avenue to make the desired genes/QTL exploitable in breeding, has consistently proved to be the transfer of only chromosome segments from the alien source, applying well established cytogenetic methodologies of "chromosome engineering" [12]. Through this approach, new allelic combinations for the target traits can be generated via meiotic pairing and recombination between the alien chromosome, or just a region of it, and its wheat counterpart, promoting the process by Ph (Pairing homoeologous) wheat mutants (available in both bread and durum wheat, see [13]), when the pairing partners share only partial homology (i.e., homoeology). This is often the case when the donor chromosome belongs to more distant wheat relatives, which, in turn, possess a lot of still untapped genetic variation. A homoeologous recombination-based strategy has the double advantage of providing well-compensated wheat-alien products, and of minimizing the size of the alien segment and consequent linkage drag, which is often responsible for the reduced fitness of sizable introgressions from wild donor species (see, e.g., [14-20]). Meeting these two requisites has in fact almost invariably resulted in successful wheat-alien transfers, even in the case of durum wheat (Triticum durum Desf., $2 \mathrm{n}=4 \mathrm{x}=28$, genome AABB), whose tetraploid nature reduces tolerance toward extensive manipulations when compared to the hexaploid bread wheat (T. aestivum L. $2 n=6 x=42$, genome AABBDD) case $[15,21]$. In the last years, tremendous scientific and technological advances are greatly expanding our knowledge of the highly complex genomes of cultivated wheats and of related Triticeae species, and hence our ability to manipulate them in a directed manner. In the following, 
the behaviour and impact on the recipient wheat genome of a variety of alien segment introgressions will be illustrated. They represent examples of "smart" chromosome engineering efforts, through which multiple breeding targets have been pursued and corresponding alien genes/QTL pyramided into wheat genotypes, also in challenging contexts, e.g., those that are determined by the tetraploid condition of durum wheat (see above), or by the presence of alien genes that affect the segregation of wheat-alien recombinant chromosomes.

\section{Stacking Different Alien Segments}

In chromosome engineering experiments, an array of wheat-alien chromosomes, with varying recombinant breakpoint positions, and hence amounts of alien chromatin, can be obtained. By genetic (molecular markers) and physical (e.g., FISH or GISH) mapping, introgressions of minimal size still containing the target gene(s) can be selected, and these in the largest majority of cases exert the best overall performance in a breeding perspective. By exploiting high-resolution tools, this goal could be achieved in several instances, both in bread and also durum wheat (see several chapters in [11] and references therein; see also [15-20]). As to the latter species, successful examples not only include the transfer of genes for resistance to diseases [14,22,23] and abiotic stresses [24], but also grain quality $[14,25-28]$ and yield-related traits $[29,30]$.

For three such transfers, each involving an alien chromosome segment that is spanning around $20 \%$ of the recipient wheat arm, an attempt was made to stack them in a single genotype. The individual transfer lines contained on wheat chromosome arms, namely 7AL, 3BS, and 1DS, distal portions of the homoeologous Th. ponticum $7 \mathrm{el}_{1} \mathrm{~L}$ arm, with the $\mathrm{Lr} 19$ (leaf rust resistance) $+\mathrm{Sr} 25$ (stem rust resistance) $+Y p$ (yellow pigment content $=\mathrm{YPC}$ ) genes [22], of the Ae. longissima 3S S arm, with the powdery mildew resistance gene Pm13 [14], and of the bread wheat 1DS arm, harbouring the Gli-D1/Glu-D3 loci, with positive effects on gluten quality [25,31]. Already at early stages of the work [32], transmission of two out the three recombinant chromosomes appeared to be normal through both germlines in $\mathrm{F}_{2}$ cross progenies. At advanced breeding stages, the result could be confirmed also for segregation of all three wheat-alien chromosomes, for which no significant difference with respect to the expected genotypic classes was detected by a $\mathrm{X}^{2}$ test of $\mathrm{F}_{2}$ progenies of the triple recombinant (RRR) after crosses and backcrosses (BC) with adapted and good-yielding varieties (Figure 1). Identification of the different genotypes was enabled by the use of polymorphic PCR-based markers associated to the alien and wheat homoeologous segments (Figure 2).

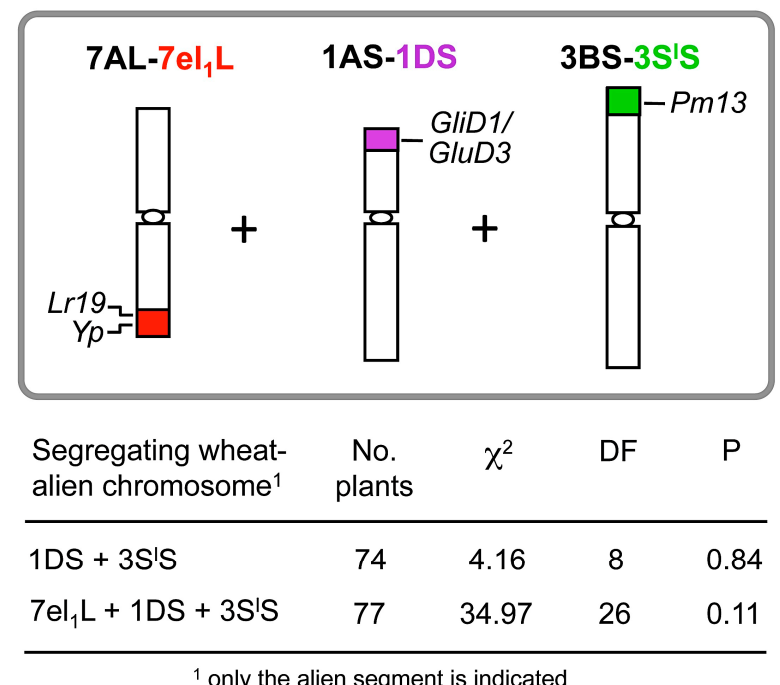

Figure 1. Wheat-alien recombinant chromosomes transferred into durum wheat and the simultaneous transmission ability of two and all three of them in $\mathrm{F}_{2}$ progenies of selfed heterozygotes. 
(a)

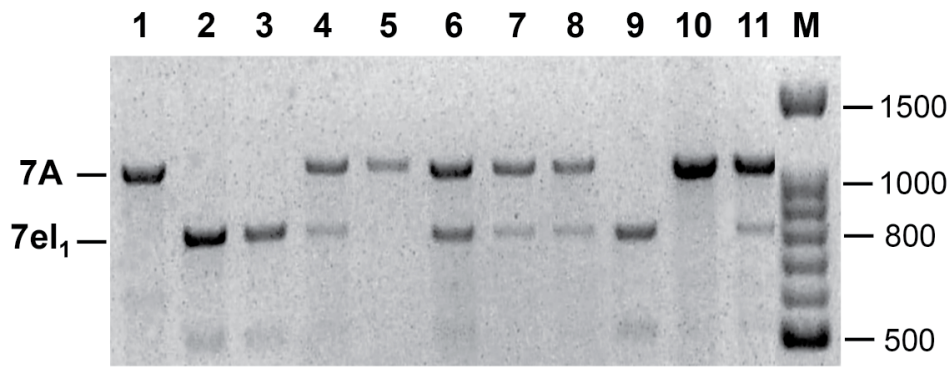

(b)

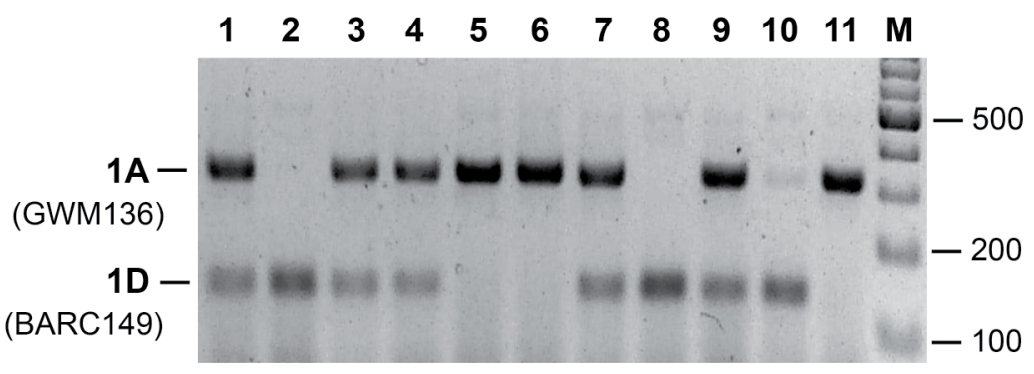

(c)

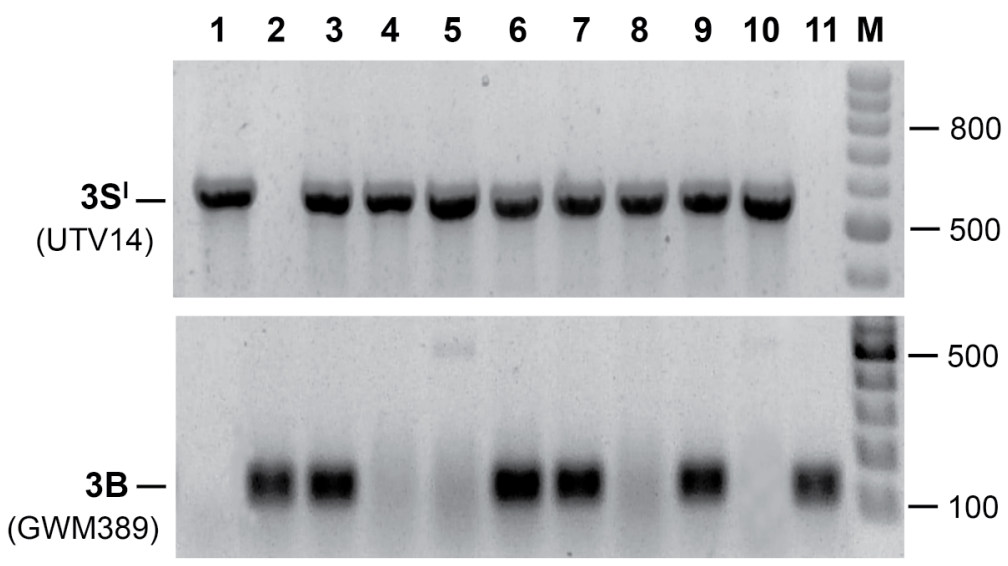

Figure 2. Profiles of PCR-based markers used to select multiple recombinant genotypes in durum wheat segregating progenies. (a) Multiplex PCR with STS (sequence tagged site) primer combination [33] generates a codominant assay for the presence of $\mathrm{Lr} 19$ and associated genes into the same $7 \mathrm{el}_{1} \mathrm{~L} T h$.

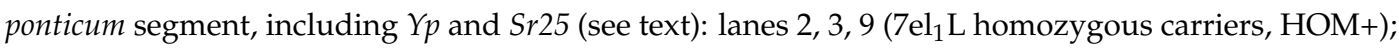

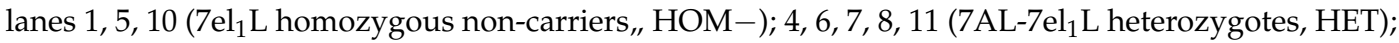
(b) Multiplex PCR with primers for SSR (simple sequence repeat) markers associated to the $1 \mathrm{AS}$ and 1DS segments, the latter including GliD1/GluD3 genes [25,26]: lanes 2, 8, 10 (1DS HOM+); lanes 5, 6, 11 (1DS HOM-); lanes 1, 3, 4, 7, 9 (1DS-1AS HET); (c) A Pm13 (3S's)-associated STS marker (UTV14, [34]), combined with a 3BS-linked SSR marker (GWM389): lanes 1, 4, 5, 8, 10 (3Sll S HOM+); lanes 2, 11 (3Sl'S HOM-); lanes 3, 6, 7, 9 (3Sl'S-3BS HET). M = 100 bp ladder (relevant base pair figures on the right side of gels).

\subsection{Agronomic Evaluation of Multiple Recombinant Lines}

Although the transmission ability of wheat-alien recombinant chromosomes represents a first, important aspect to assess their impact on the recipient genotype (see also ahead), the effect on yield remains the most critical parameter in a breeding perspective. In the majority of cases, yield reduction due to linkage drag is a major problem when introgressing alien chromatin into durum wheat $[14,29,30,35]$. The three transfer chromosomes that are described above (Figure 1) had shown no major effects on yield, also when combined in a single genotype. However, this evidence was 
mostly based on small-scale field tests, or it was somewhat biased by leaf-rust epidemics, which could have favoured Lr19-bearing genotypes [25]. In the 2015 season, a large-scale comparative field trial, including several currently grown national varieties, selected recombinant genotypes (R117) bearing one, two, or three of the alien segments, and the cultivated varieties mostly involved in the pedigree of the R117 lines (i.e., the Italian cv. Simeto and the French cv. Karur), was carried out in Viterbo (Central Italy).

The analysis of co-variance (ANCOVA), focused on the R117 lines and the latter two varieties, taken as controls, showed significant differences between the genotypes for several of the traits that were measured (Table 1).

For most of the phenotypic attributes (see HD, PH, GNS, and TGW), recombinant (R117) genotypes generally displayed a closer resemblance with $\mathrm{cv}$. Karur, as expected from its major contribution to the $\mathrm{R} 117$ pedigree ( $3 \mathrm{BC}$ s preceding four self generations, i.e., $\mathrm{BC}_{3} \mathrm{~F}_{4}$ progenies).

As for the main productivity traits (SNM2, BM2, GYM2, GNM2, and HI), the values of R117 lines resulted to be essentially at the level of control cultivars, or superior to them (see GYM2, GNM2, HI). This important result shows that the presence of one, two, or even three alien chromosome segments of relatively small size (Figure 1), originating from genetic pools more or less distant from durum wheat, did not cause any yield penalty on the recipient genotype. Instead, in the case of genotypes R117-11-20 (triple recombinant) and R117-11-8 (recombinant for the Th. ponticum segment only), yield per unit area (GYM2) was increased of about $10 \%$ vs. Karur and $24-30 \%$ vs. Simeto. It can be noted that this increase was principally due to increase in grain number (GNM2; $+3-55 \%$ ), biomass (BM2; $+2-16 \%$ ), and consequently, harvest index (HI; $+8-10 \%)$, the latter trait being increased in all of the recombinants except R117-9-59 (Table 1). Furthermore, introgression of different alien segments significantly increased some of the spike fertility traits: GNS in recombinants R117-11-20 and R117-2-21 (+5-33\%), GYS in R117-11-20 (+7-36\%), and GNSP in R117-11-20 and R117-11-8 (+4-20\%). This suggests that the increase of yield per spike was a key determinant of the final yield increase, especially of the two most productive recombinants (R117-11-20 and R117-11-8).

Enhancement of yield per unit area and per spike of the triple recombinant R117-11-20 validates, in fact, preliminary results from the earlier field study that was carried out on spaced plants of the triple recombinant genotype, before its BCs with cv. Karur [25]. For example, spike fertility traits, such as GNS and GNSP, which in the case of R117-11-20 reached 10\% and $20 \%$ increases, respectively, were increased by $3-10 \%$ in the original triple recombinant [25]. Similarly, the observed increase of up to $30 \%$ of grain yield per unit area of R117-11-20 genotype is in line with the $60 \%$ yield increase that was formerly exhibited in one location of the Central-West Italy [25]. However, with respect to the previous trials, results from the 2015 season were obtained in a leaf rust-free environment, which was subjected to an appropriate disease management: this emphasizes the positive effect of the introgressed segments on yield per se, irrespective of the advantage conferred by the Lr19 gene, present in all recombinant genotypes (Table 1). 
Table 1. Mean values of yield-related traits ${ }^{1}$ recorded on recombinant and control durum wheat genotypes in 2015 growing season and $p$-values from the ANCOVA analysis. Letters in each row correspond to the ranking of Tukey HSD test at $p<0.05$.

\begin{tabular}{|c|c|c|c|c|c|c|c|c|c|c|c|c|c|c|c|c|c|}
\hline Genotype/Trait ${ }^{1}$ & R117-11-20 & & R117-9-11 & & R117-9-71 & & R117-2-21 & & R117-9-59 & & R117-11-8 & & cv. Karur & & cv. Simeto & & ANCOVA $p$-Value ${ }^{2}$ \\
\hline$L r 19+Y p$ & + & & + & & + & & + & & + & & + & & - & & - & & \\
\hline Glu-D3 & + & & + & & + & & + & & + & & - & & - & & - & & \\
\hline Pm13 & + & & + & & + & & - & & - & & - & & - & & - & & \\
\hline $\mathrm{HD}$ & 115.0 & $\mathrm{~b}$ & 118.3 & $\mathrm{a}$ & 117.7 & $a b$ & 116.3 & $a b$ & 117.3 & $a b$ & 116.3 & $a b$ & 115.7 & $a b$ & 106.7 & c & $0.000^{* * *}$ \\
\hline PH & 73.3 & $a b$ & 66.7 & c & 66.7 & c & 72.3 & $a b c$ & 67.0 & c & 70.0 & $\mathrm{bc}$ & 71.3 & $\mathrm{bc}$ & 78.3 & a & $0.000^{* * *}$ \\
\hline SNM2 & 195.4 & & 182.4 & & 158.8 & & 170.6 & & 147.1 & & 195.4 & & 200.7 & & 181.7 & & 0.332 \\
\hline BM2 & 759.0 & & 710.8 & & 628.0 & & 628.8 & & 559.6 & & 763.9 & & 741.4 & & 659.5 & & 0.458 \\
\hline GYM2 & 319.8 & & 281.1 & & 249.6 & & 266.4 & & 214.2 & & 323.8 & & 291.1 & & 248.9 & & 0.254 \\
\hline GNM2 & 6328.5 & & 6031.5 & & 5192.9 & & 5432.1 & & 4334.1 & & 6293.8 & & 6133.0 & & 4070.0 & & 0.096 \\
\hline HI & 0.42 & & 0.40 & & 0.40 & & 0.42 & & 0.38 & & 0.42 & & 0.39 & & 0.38 & & 0.164 \\
\hline GYS & 3.0 & a & 2.4 & $\mathrm{~b}$ & 2.6 & $a b$ & 2.7 & $a b$ & 2.6 & $a b$ & 2.7 & $\mathrm{ab}$ & 2.5 & $\mathrm{ab}$ & 2.8 & $\mathrm{ab}$ & $0.035^{*}$ \\
\hline GNSP & 3.0 & a & 2.6 & b & 2.8 & $\mathrm{ab}$ & 2.8 & $\mathrm{ab}$ & 2.6 & $\mathrm{~b}$ & 2.9 & $\mathrm{a}$ & 2.5 & $\mathrm{~b}$ & 2.8 & $a b$ & $0.000^{* * *}$ \\
\hline TGW & 50.8 & $\mathrm{bc}$ & 46.6 & c & 47.3 & $\mathrm{bc}$ & 49.0 & $\mathrm{bc}$ & 49.5 & $\mathrm{bc}$ & 51.4 & $\mathrm{~b}$ & 47.1 & c & 61.1 & $\mathrm{a}$ & $0.000^{* * *}$ \\
\hline
\end{tabular}

${ }^{1} \mathrm{HD}$, heading date; $\mathrm{PH}$, plant height; SNM2, spike number $\mathrm{m}^{-2}$; $\mathrm{BM} 2$, biomass $\mathrm{m}^{-2}$; GYM2, grain yield $\mathrm{m}^{-2}$; GNM2, grain number $\mathrm{m}^{-2}$; HI, harvest index; GNS, grain number spike ${ }^{-1}$,

GYS, grain yield spike ${ }^{-1}$; GNSP, grain number spikelet ${ }^{-1}$; TGW, thousand grain weight; ${ }^{2 *}{ }^{2 * *}$ and ${ }^{* * *}$ indicate significant $\mathrm{F}$ values at $p<0.05, p<0.01$ and $p<0.001$, respectively. 


\subsection{Breeding Potential of the Triple Recombinant}

From the breeding point of view, the R117-11-20 line, homozygous for the 7A-7el $1,1 \mathrm{~A}-1 \mathrm{D}$ and $3 \mathrm{~B}-3 \mathrm{~S}^{1}$ recombinant chromosomes (Figure 1), resulted in the most promising and most productive out of the six recombinant genotypes when compared to control varieties. The sister line tested, namely R117-9-11, had a good, though not equally outstanding, performance, indicating a particularly favourable allelic combination in the background genotype of R117-11-20. The latter, as the original triple recombinant used in BCs to cv. Karur, contains in its pedigree also cv. Simeto. A comparison among the three genotypes highlights the differences for the most relevant yield-related traits associated with the triple alien introgression (Table 2).

Table 2. Percentage differences between R117-11-20 triple recombinant line and the two control cultivars Karur and Simeto for the relevant yield traits (see Table 1 for symbols).

\begin{tabular}{ccc}
\hline Trait & Difference vs. Karur & Difference vs. Simeto \\
\hline SNM2 & $-3 \%$ & $8 \%$ \\
BM2 & $2 \%$ & $15 \%$ \\
GYM2 & $10 \%$ & $28 \%$ \\
GNM2 & $3 \%$ & $55 \%$ \\
HI & $8 \%$ & $11 \%$ \\
TGW & $8 \%$ & $-17 \%$ \\
GNS & $10 \%$ & $30 \%$ \\
GYS & $20 \%$ & $7 \%$ \\
\hline
\end{tabular}

Almost all of traits considered, directly or indirectly involved in final yield formation, showed increased values in the novel recombinant with respect to the two varieties, with positive effects being more evident vs. Simeto, the older cultivar of the two (Table 2). Final yield (GYM2) of R117-11-20 was remarkably higher than that of both the controls, yet the traits that contributed the most to this result seem to be different for each cultivar. When compared to Karur, spike yield parameters, i.e., GNS, GYS, and TGW, were those displaying higher values in the R117-11-20 recombinant $(+10 \%, 20 \%, 8 \%$, respectively). On the other hand, in comparison with Simeto, not only grain number spike ${ }^{-1}$ (GNS, $+30 \%$ ), but also spikes number $\mathrm{m}^{-2}$ (SNM2, $+8 \%$ ), seem to have caused the considerable increase of grain number (GNM2) and grain yield (GYM2) per unit area. R117-11-20 is a valid example of unconventional breeding, where intraspecific and interspecific variation have been usefully combined to give enhanced yield potential and novel quality attributes to the durum wheat crop.

\section{Assembling Genes from Different Alien Sources into the Same Segment}

An alternative strategy to enrich a given wheat genotype with multiple alien traits consists of bringing together into a single alien chromosome segment genetic material originating from diverse though closely related sources. The re-engineered chromosomes with the desired novel assembly are the result of recombination between alien segments (either homologous or homoeologous) previously incorporated into different parental translocation lines. Various beneficial genes can thus be accumulated, and unwanted genes possibly eliminated. Particularly noteworthy examples of this strategy concern gene combinations from perennial Triticeae species of the Thinopyrum genus, one of the richest sources of valuable genes/QTL for wheat improvement [36,37]. By means of ph1b-mediated recombination between a bread wheat-Th. ponticum $\mathrm{T} 4$ translocation $\left(70 \%\right.$ of the alien $7 \mathrm{el}_{1} \mathrm{~L}$ arm into wheat 7DL) and a homoeologous Th. intermedium segment, also on 7DL, the highly effective leaf rust resistance gene Lr19 from the former and the barley yellow dwarf virus resistance gene $B d v 2$ from the latter were recently combined $[17,38]$. Similarly, and in this case exploiting the high degree of homology relating two group 7 chromosomes (named $7 \mathrm{el}_{1}$ and $7 \mathrm{el}_{2}$ ) of different Th. ponticum accessions, the $\mathrm{Lr} 19$ gene (located on the $7 \mathrm{el}_{1} \mathrm{~L}$ arm) was pyramided, both in bread wheat [39-41] and 
in durum wheat [41], with Fhb-7el2, a major QTL for resistance to Fusarium head blight (FHB) mapped on $7 \mathrm{el}_{2} \mathrm{~L}$ (recently renamed $\mathrm{Fhb7}$ [42]).

A remarkable successful attempt [43] involved the bread wheat $\mathrm{T} 4$ translocation line, containing Lr19 and associated genes/QTL on the Th. ponticum $7 \mathrm{el}_{1} \mathrm{~L}$ portion, and the bread wheat $\mathrm{cv}$. Chinese Spring (CS) 7E(7D) substitution line, which was used as donor parent of an exceptionally effective FHB resistance locus associated with the Th. elongatum 7EL arm (Fhb-7EL). In this case, due to the close homoeology relating the $7 \mathrm{el}_{1} \mathrm{~L}$ and 7EL arms, as confirmed by cytological (meiotic chromosome pairing) and molecular (genetic map synteny and collinearity) evidence [43], even in the absence of any genetic pairing promotion (e.g., ph1 mutation), target genes from the two Thinopyrum species could be brought together in a single alien segment on wheat 7DL with relative ease. The array of segregating progeny from the cross between the two donor lines has been recently widened. The 114 total plants tested with appropriate molecular markers (Figure 3), have revealed a total frequency of recombinant types of over $14 \%$, which is higher than the $10.6 \%$ that was previously estimated on a smaller sample [43]. Of these, equal number of $\mathrm{T} 4$ and 7E types were isolated in the cross progeny of $\left(\right.$ CS7E(7D) $\times$ T4) $\mathrm{F}_{1}$ s with normal bread wheat cultivars, used as pollen parents (Figure 3).

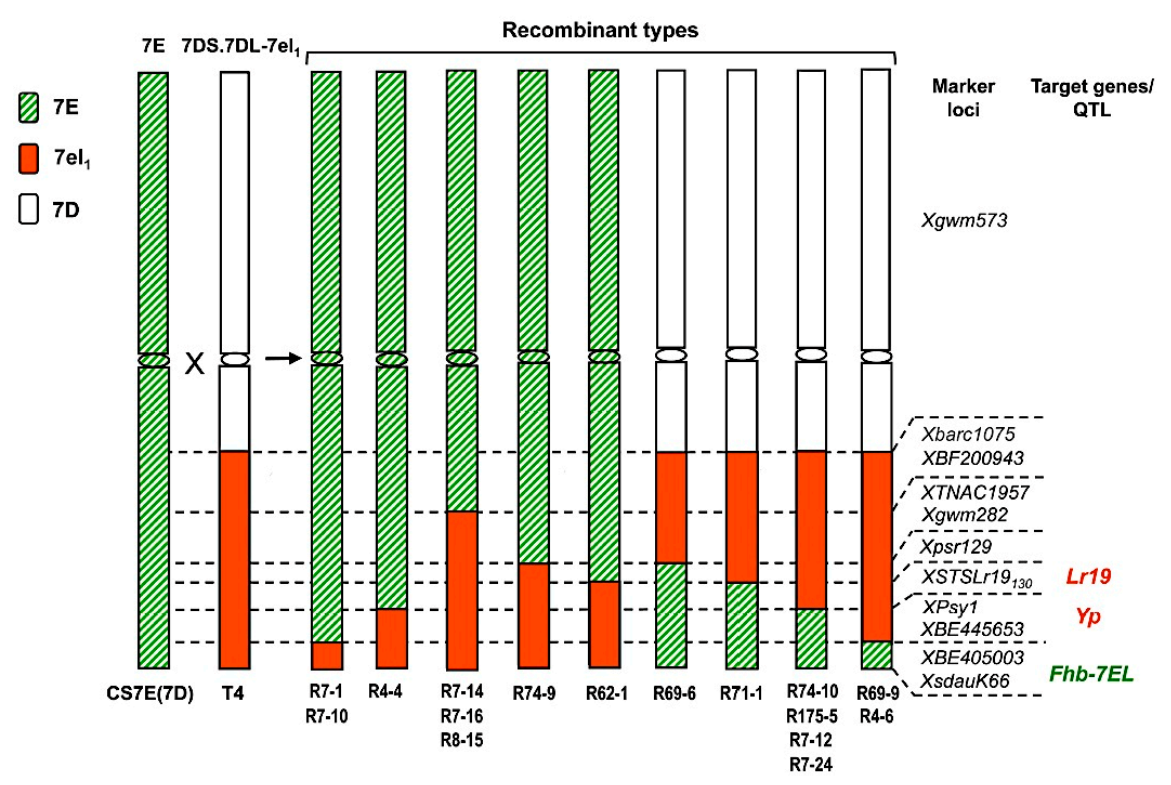

Figure 3. Cytogenetic maps of group-7 chromosomes of parental and recombinant genotypes identified in cross progenies of $(\mathrm{CS} 7 \mathrm{E}(7 \mathrm{D}) \times \mathrm{T} 4) \mathrm{F}_{1} \mathrm{~s}$ with normal bread wheat cultivars, based on molecular marker and GISH analyses. $7 \mathrm{EL}-7 \mathrm{el}_{1} \mathrm{~L}$ and $7 \mathrm{DL}-7 \mathrm{el}_{1} \mathrm{~L}$ breakpoints are indicated by dashed lines. Only a subset of tested markers is reported; for additional marker data see [43].

In a breeding perspective, the T4 recombinant types are the most suitable. Among them, particularly promising are those that carry all of the target genes, such as R74-10 (and so R175-5, R7-12 and R7-24), bearing Lr19 from Th. ponticum $7 \mathrm{el}_{1} \mathrm{~L}$, combined with the Fhb-7EL major QTL from Th. elongatum, conferring an outstanding resistance to Fusarium most threatening diseases worldwide, i.e., FHB as well as crown rot [43]. This group of recombinants carries a 7EL allele for the YPC phenotype (Psy1 gene), which is associated with reduced flour yellowness, and is hence more desirable for bread wheat breeding [43]. On the other hand, recombinant types R69-9 and R4-6, with less 7EL distal chromatin (Figure 3), possess a $7 \mathrm{el}_{1} \mathrm{~L}$ allele for $P$ sy 1 gene, determining a higher YPC [43]; thus, they are the most suited donor lines for the ongoing transfer of the Lr19 + Fhb-7EL combination into durum wheat.

Identification and characterization of the various recombinant types was enabled by use of GISH (genomic in situ hybridization) and by several molecular markers (see Figure 3 and [43]), which highlighted the different $7 E L-7 \mathrm{el}_{1} \mathrm{~L}$ breakpoints. The most polymorphic and user-friendly of 
such markers (e.g., Figure 4) represent a valuable tool for assisted selection (MAS) of recombinant chromosomes with the novel gene combinations in breeding programs.
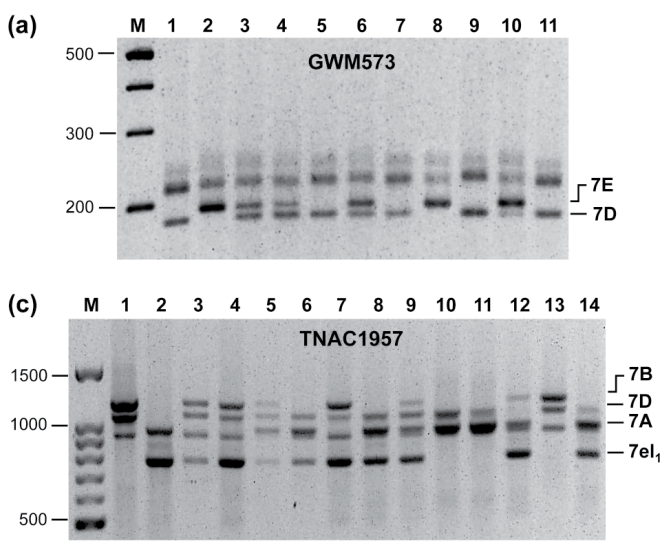
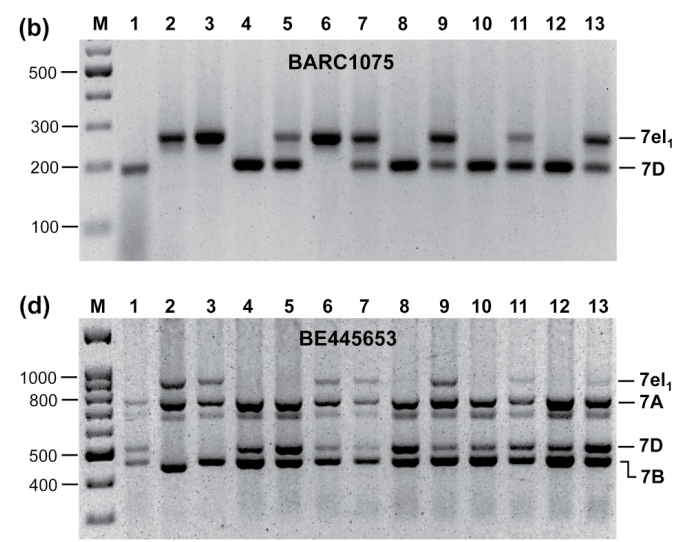

Figure 4. Profiles of some PCR-based markers used to select recombinant chromosomes with gene combinations from $\mathrm{Th}$. ponticum $7 \mathrm{el}_{1} \mathrm{~L}$ and $\mathrm{Th}$. elongatum $7 \mathrm{EL}$ arms in cross progenies of $(\mathrm{CS7E}(7 \mathrm{D}) \times \mathrm{T} 4) \mathrm{F}_{1} \mathrm{~s}$ with normal bread wheat cultivars (CS and Blasco). Group-7 wheat and Thinopyrum spp. alleles are indicated. (a) GWM573, a short arm-linked marker (7DS and 7ES alleles), allows discrimination between T4 and 7E chromosome types (both parental and recombinant): lane 1, Blasco (7DS); lane 2, CS7E(7D), 7ES; lanes 3-11, segregating progeny, homozygous (HOM+) for the 7ES allele (8), for the 7DS allele (i.e., 7ES HOM-: 5, 7, 9, 11) or heterozygous (7ES-7DS HET: 3, 4, $6,10)$; (b) BARC1075 highlights a $7 \mathrm{el}_{1} \mathrm{~L}$ and a 7DL allele: lane 1, Blasco (7DL); lane 2, T4 (7el $\left.{ }_{1} \mathrm{~L}\right)$; lanes 3-13, 7el ${ }_{1} \mathrm{~L} \mathrm{HOM}+(3,6) ; 7 \mathrm{el}_{1} \mathrm{~L} \mathrm{HOM}_{-}(4,8,10,12)$ and $7 \mathrm{el}_{1} \mathrm{~L}-7 \mathrm{DL} \mathrm{HET}(5,7,9,11,13)$ segregates; (c) TNAC1957: lane 1, Blasco (7DL allele); lane 2, T4 (7el ${ }_{1} \mathrm{~L}$ allele); lanes 3-14: 7el ${ }_{1} \mathrm{~L} \mathrm{HOM}$ (12); 7el ${ }_{1} \mathrm{~L}$ HOM - $(10,11,13)$ and $7 \mathrm{el}_{1}$ L-7DL HET $(3-9,14)$ segregates for the two critical alleles; (d) BE445653: lane 1, Blasco (7DL allele); lane 2, T4 (7el 1 L allele); lanes 3-13, 7el ${ }_{1} \mathrm{~L} \mathrm{HOM+} \mathrm{(3),} \mathrm{7el}{ }_{1} \mathrm{~L} \mathrm{HOM}-(4,5,8$, $10,12)$ and $7 \mathrm{el}_{1} \mathrm{~L}-7 \mathrm{DL} \operatorname{HET}(6,7,9,11,13)$ segregates for the two critical alleles. $M=100$ bp ladder (relevant base pair figures on the left side of gels).

\section{An Intriguing Issue in Wheat-Alien Gene Transfer: Segregation Distortion}

A fairly frequently observed phenomenon upon the introduction of an alien chromosome or a rearranged wheat-alien chromosome into the wheat genome is its abnormal segregation in progenies from heterozygotes. Segregation distortion (SD) with respect to expected Mendelian ratios is of widespread occurrence in plant and animal species, for which it is an important evolutionary force [44-47]. SD is likely to represent one result of genetic incompatibilities between parental genomes that have been separated by reproductive barriers [48]. In this view, it is not surprising to find the level of SD to increase, both in the number of SD regions (SDRs) within a chromosomal set, and in the number of markers within each SDR, in intraspecific cross progeny involving genetically and geographically more distant parents [49]. In contrast to the latter work, which was carried out on wheat, a recent study on $\mathrm{F}_{2}$ populations generated from several Arabidopsis thaliana accessions showed little correlation between the degree of genetic differentiation between the parental accessions and the probability of observing allelic distortion in their progeny [50]. Nonetheless, many cases of SD were discovered in interspecific contexts, although this evidence, as suggested by Seymur et al. [50], may not be due to a higher occurrence of the phenomenon in such contexts, but because the severity of distortion is more extreme (hence more easily detectable), and more rapidly reaching fixation in the absence of species-specific modifiers.

Since SD can affect accuracy of linkage map construction and also have breeding implications, it has been addressed in several studies involving crop species, including wheat (e.g., [47,49,51-53]). In progeny of wheat-alien combinations, one of the most likely causes for the skewed transmission of complete or segmental alien chromosomes of various wild species (most studied those from 
Aegilops and Thinopyrum genera) has been suggested to be gametophytic competition during zygote formation, with male gametogenesis being affected in the majority, though not all of the cases [36,54,55]. The phenomenon, however, proved to be highly variable even for a given SDR containing a segregation distortion $(S d)$ gene, going from selective or even exclusive retention in the wheat background through generations (preferential transmission), to a more or less dramatic self-elimination. Such changes in the direction and magnitude of the effects of $S d$ genes have been associated to allelic variation at several wheat "responder" loci, with the background genetic/chromosomal environment thus strongly conditioning the SD phenotype [56-64].

For $S d$ genes that prevailingly or exclusively determine the preferential transmission of the carrier chromosome, the term $G c$ (gametocidal) is usually adopted, which is suggestive of the underlying mechanism of action. When in heterozygous or hemizygous condition, such genes in fact "kill" gametes lacking them, by causing chromosome breakages and various consequent aberrations, mainly in the course of post-meiotic divisions of micro- and macro-sporogenesis [54,55,65]. Both male and female gametes without the Gc gene (e.g., normal wheat types) become abortive, and as a result, only gametes with the $G c$ gene (and thus, with the alien or wheat-alien chromosome) are transmitted to the next generation. As such, Gc genes are typical selfish genetic elements [48]. Besides those that were identified on various chromosomes of many Aegilops species [54,55,65], Sd genes with more or less marked characteristics of $G c$ elements were detected on group 7 chromosomes of polyploid Thinopyrum species, including Th. intermedium [66] and Th. ponticum $[36,58,59,61,64]$. The Th. ponticum largely homologous $7 \mathrm{el}_{1} \mathrm{~L}$ and $7 \mathrm{el}_{2} \mathrm{~L}$ chromosome arms, both contain one or more $S d$ genes, which have been studied rather intensively, primarily because of the linked beneficial genes of breeding relevance (see above in this section, and Section 2). The SD phenotype determined by $S d$ gene(s)/SDR(s) that is linked to the $7 \mathrm{el}_{1} \mathrm{~L}$ segment of translocation line $\mathrm{T} 4$ and of other bread and durum wheat lines possessing the same or shorter $7 \mathrm{el}_{1} \mathrm{~L}$ portions, exemplifies the highly variable, probably background-dependent, outcomes, as described earlier (reviewed in [36]). On the other hand, the effects of the $7 \mathrm{el}_{2} \mathrm{~L}$-linked $S d$ gene(s) appear relatively more consistent through studies and backgrounds. What seems to be the result of a gametocidal type of action, confers to the entire $7 \mathrm{el}_{2}$ chromosome or portions of it a marked preferential transmission from heterozygous wheat carrier lines. However, not always the same germline appears to be affected: female gametes were reported to be exclusively involved in the first observations [58,59], while male gametes were later indicated as being implicated in the almost uniparental segregation [64]. In the latter study, the phenomenon was analysed in recombinant inbred lines (RILs) from the cross between wheat substitution lines for the complete $7 \mathrm{el}_{2}$ and $7 \mathrm{el}_{1}$ chromosomes in cv. Thatcher background. A survey of the RILs progeny with molecular markers revealed a clear-cut disproportion of $7 \mathrm{el}_{2}$-linked marker alleles preferentially transmitted through the male germline. The effect of $7 \mathrm{el}_{1}$-associated $S d$ genes was virtually undetectable when co-present with $7 \mathrm{el}_{2}$, evidently stronger/dominant over $7 \mathrm{el}_{1}$ for its gametocidal action, similarly to what observed for the interaction of Gc genes from different Aegilops species (reviewed in [54]).

The prevailing or almost exclusive SD/Gc effect of $7 \mathrm{el}_{2}$ was confirmed in a subsequent study, in which $S d$ genes/SDRs that are associated to $7 \mathrm{el}_{1} \mathrm{~L}$ and $7 \mathrm{el}_{2} \mathrm{~L}$ arms were brought together in the cross progeny of [KS24-1 (7DL·7 $\mathrm{el}_{2} \mathrm{~L}$ centric translocation line) $\times \mathrm{T} 4$ (7DS·7DL-7el ${ }_{1} \mathrm{~L}$ translocation line)] $\times$ cv. Blasco [41]. In this context, a further different picture emerged, again likely influenced by the background genotype. While in $\mathrm{F}_{1} \mathrm{~s}$ after pollination with Blasco a preferential transmission of $7 \mathrm{el}_{2} \mathrm{~L}$ marker alleles through female gametes was observed, transmission of recombinant $7 \mathrm{el}_{1} \mathrm{~L}-7 \mathrm{el}_{2} \mathrm{~L}$ chromosomes in the resulting $\mathrm{F}_{2}$ progenies apparently followed a "bimodal" behaviour, being normal for some of them, while significantly deviating from the 1:2:1 ratio for others (Table 3). The relative abundance of the segregating genotypes in the latter progenies suggests that preferential transmission probably occurred through both germlines, as homozygous recombinant segregates $(\mathrm{HOM}+)$ were very frequent, more than the heterozygotes (HET) in some progenies, while the homozygous non-recombinant segregates $(\mathrm{HOM}-)$ were almost absent in all of them (Table 3$)$. 
When comparing the allele type of the several markers tested for progeny genotyping, it appeared that, irrespective of other $7 \mathrm{el}_{1} \mathrm{~L}$ vs. $7 \mathrm{el}_{2} \mathrm{~L}$ regions, the one comprising PSP3123, BARC172, and BF200943 (highlighted in Figure 5), was critical in determining the SD outcome; in fact, all of the recombinant chromosomes possessing $7 \mathrm{el}_{2} \mathrm{~L}$ alleles at these marker loci were preferentially transmitted (Table 3 and Figure 5).

As shown in Figure 5, the work of Forte et al. [41] enabled a higher map resolution than previously achieved [64], separating this SDR from a more proximal one, containing the PSR129 marker, associated, in turn, to $7 \mathrm{el}_{1} \mathrm{~L}$-linked SD effects in various studies and materials (both bread and durum wheat recombinant lines, see [36] for a review). Within the $7 \mathrm{el}_{2} \mathrm{~L} \mathrm{SDR}$, it seems of interest to note the presence of a wheat EST (Expressed Sequence Tag), namely BF200943, for whose nucleotide sequence a BLAST search (https:/ / blast.ncbi.nlm.nih.gov/Blast.cgi) indicated a high homology with a protein product belonging to the mitogen-activated protein kinase (MAPK) cascades of several Triticeae species. MAPKs are ubiquitous signaling modules in eukaryotes, which are involved in the regulation of different developmental processes. They play a crucial role in proliferation, differentiation, and cycle regulation in germ cells of different mammalian species [67]. MAPKs are also involved in almost every aspect of plant growth and development. As to plant reproduction, MAPKs play vital roles in various stages, including anther, pollen, ovule, and seed development [68].

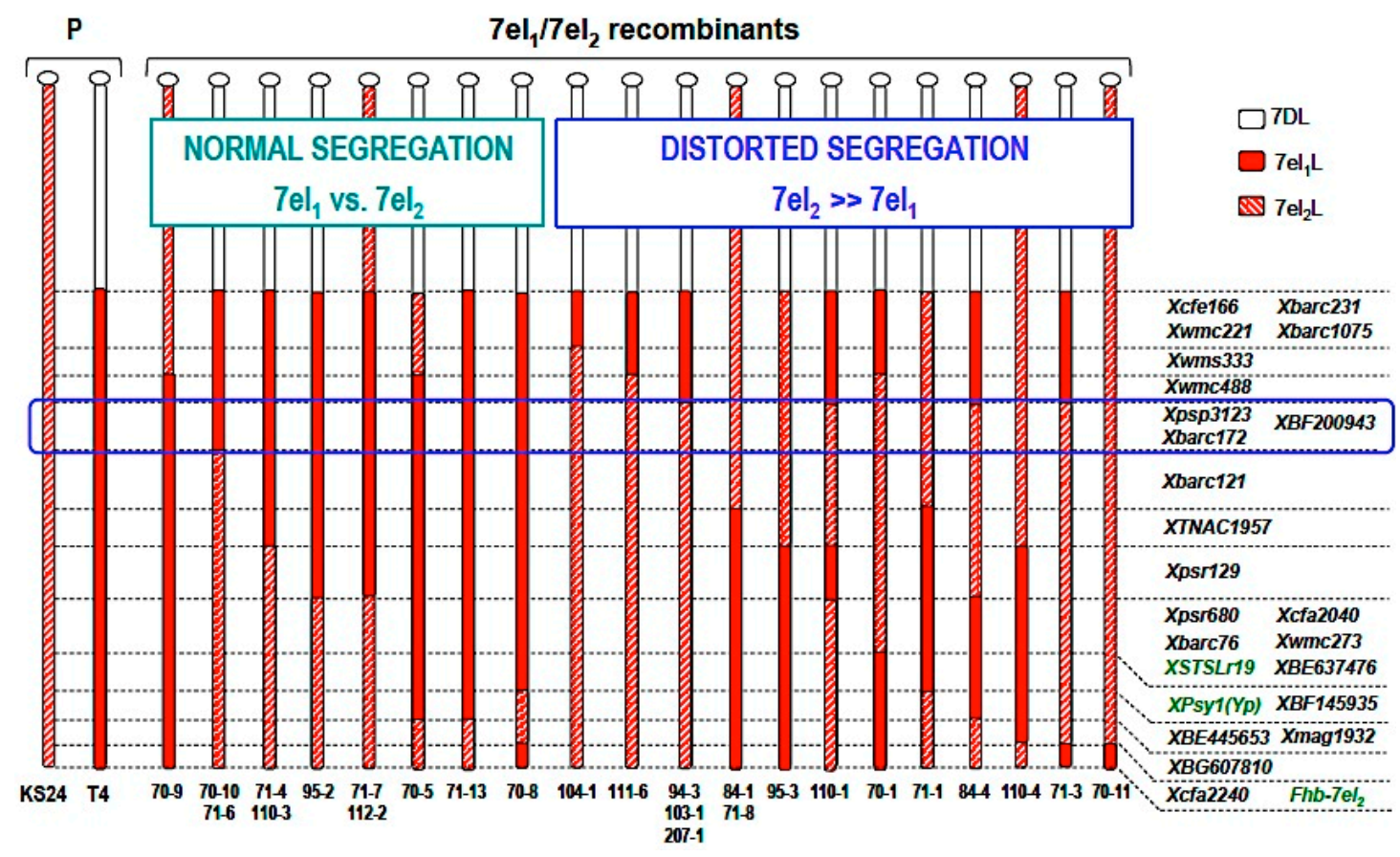

Figure 5. Cytogenetic maps of the 7DL-7el ${ }_{1} \mathrm{~L} / 7 \mathrm{el}_{2} \mathrm{~L}$ arms of bread wheat-Th. ponticum recombinant chromosomes, isolated from KS24-1/T4/cv. Blasco crosses, based on molecular marker analysis and genomic in situ hybridisation (GISH). Dotted lines indicate the $7 \mathrm{DL} / 7 \mathrm{el}_{1} \mathrm{~L} / 7 \mathrm{el}_{2} \mathrm{~L}$ breakpoints. The location of the $7 \mathrm{el}_{2} \mathrm{~L}$ region that is likely to have the main effect on segregation distortion observed in this context (see text), is bounded by the violet box. P = parental lines. Modified from Forte et al., 2014 [41]. 
Table 3. Segregation in $F_{2}$ progenies from the KS24-1/T4/cv. Blasco cross and allele type of some of the markers used for progeny genotyping (see also Figure 5).

\begin{tabular}{|c|c|c|c|c|c|c|c|c|c|c|}
\hline \multirow{2}{*}{ Rec. No. } & \multirow{2}{*}{ Chrom. Type } & \multicolumn{4}{|c|}{ Marker Alleles } & \multicolumn{5}{|c|}{$F_{2}$ Segregation } \\
\hline & & BF200943 PSP3123 BARC172 & BARC 121 & TNAC 1957 & PSR 129 & HOM+ & HET & HOM- & $\mathrm{X}^{2}$ 1:2:1 & $p$ Value \\
\hline $70-5$ & $\mathrm{~T} 4$ & $7 \mathrm{el}_{1}$ & $7 \mathrm{el}_{1}$ & $7 \mathrm{el}{ }_{1}$ & $7 \mathrm{el}_{1}$ & 9 & 19 & 7 & 0.49 & 0.78 \\
\hline $70-8$ & $\mathrm{~T} 4$ & $"$ & $"$ & $"$ & $"$ & 6 & 24 & 13 & 2.86 & 0.24 \\
\hline $70-9$ & KS24 & $"$ & $"$ & $"$ & $"$ & 8 & 10 & 5 & 1.18 & 0.55 \\
\hline $71-7$ & KS24 & $"$ & $"$ & $"$ & $"$ & 5 & 11 & 10 & 2.54 & 0.28 \\
\hline $71-13$ & $\mathrm{~T} 4$ & $"$ & $"$ & $"$ & $"$ & 4 & 7 & 5 & 0.38 & 0.83 \\
\hline $95-2$ & $\mathrm{~T} 4$ & $"$ & $"$ & $"$ & $"$ & 4 & 7 & 1 & 1.83 & 0.40 \\
\hline $110-3$ & $\mathrm{~T} 4$ & $"$ & " & " & $7 \mathrm{el}_{2}$ & 5 & 11 & 5 & 0.04 & 0.98 \\
\hline $70-10$ & $\mathrm{~T} 4$ & $"$ & $7 \mathrm{el}_{2}$ & $7 \mathrm{el}_{2}$ & $"$ & 2 & 8 & 2 & 1.33 & 0.51 \\
\hline $71-6$ & $\mathrm{~T} 4$ & $"$ & " & " & $"$ & 3 & 8 & 1 & 2.00 & 0.37 \\
\hline 70-1 & $\mathrm{T} 4$ & $7 \mathrm{el}_{2}$ & $"$ & $"$ & $"$ & 5 & 14 & 0 & 6.89 & 0.03 * \\
\hline $70-11$ & KS24 & $"$ & $"$ & $"$ & $"$ & 9 & 13 & 0 & 8.09 & 0.02 * \\
\hline $71-3$ & $\mathrm{~T} 4$ & $"$ & $"$ & $"$ & $"$ & 8 & 16 & 0 & 8.00 & $0.02 *$ \\
\hline $84-4$ & $\mathrm{~T} 4$ & $"$ & $"$ & $"$ & $"$ & 21 & 13 & 0 & 27.82 & $0.000^{* * *}$ \\
\hline $94-3$ & $\mathrm{~T} 4$ & $"$ & $"$ & $"$ & $"$ & 9 & 18 & 0 & 9.02 & $0.01 *$ \\
\hline $111-6$ & $\mathrm{~T} 4$ & $"$ & $"$ & $"$ & $"$ & 16 & 10 & 3 & 14.45 & $0.001^{* *}$ \\
\hline $110-1$ & $\mathrm{~T} 4$ & $"$ & $"$ & $"$ & $7 \mathrm{el}_{1}$ & 10 & 8 & 0 & 7.33 & 0.03 * \\
\hline $110-4$ & KS24 & $"$ & $"$ & $"$ & $"$ & 10 & 13 & 1 & 6.92 & 0.03 * \\
\hline $71-8$ & KS24 & $"$ & $"$ & " & $"$ & 8 & 8 & 0 & 8.00 & 0.02 * \\
\hline $84-1$ & KS24 & $"$ & $"$ & $"$ & $"$ & 9 & 9 & 0 & 6.79 & 0.03 * \\
\hline
\end{tabular}

$1 * * *$ and ${ }^{* * *}$ indicate significant differences at $p<0.05, p<0.01$ and $p<0.001$, respectively 
At this stage of knowledge, a possible involvement in the observed SD phenotype of a $7 \mathrm{el}_{2}$ putative variant allele of the BF200493 gene can only be a matter of speculation. Indeed, despite the apparent ubiquity of segregation distortion, the relative contribution of different biological processes, such as epistatic incompatibilities, gametic selection, or meiotic drive, is often unclear, especially in plants [50]. Even when the mechanism is relatively well described, as in the case of $G c$ factors [54,55], still, little information is available on the molecular basis of the phenomenon. Studies of a range of different Gc chromosomes/factors suggest that there are at least two types of elements that are associated with the mechanism responsible for their preferential transmission: the breaker element, causing extensive chromosomal breakage, and hence the lethality of gametes not carrying the Gc chromosome/factor, and the inhibitor element, preventing these effects in gametes retaining the Gc chromosome/factor (reviewed in [54]).

The two phenotypes that are controlled by such elements were hypothesized to be at the basis of the preferential transmission of the Ae. sharonensis $4 \mathrm{~S}^{\text {sh }}$ chromosome, with the breaker element ( $G c 2$ or $G c B$ ) being initially mapped to the distal end of the long arm [51], and later more precisely assigned to the region immediately proximal to a block of sub-telomeric heterochromatin on $4 S^{\text {sh }} \mathrm{L}$ arm [69]. Recently, comparative genomic studies, coupled with deletion mapping and targeted-capture sequencing, have enabled the identification of unique single nucleotide polymorphisms (SNPs) that are specific to the short Ae. sharonensis $4 \mathrm{~S}^{\text {sh }} \mathrm{L}$ segment introgressed into wheat and associated to the Gc phenotype, of which 18 represent candidate genes for the $4 S^{\text {sh }} \mathrm{L}$ breaker element [70]. One of these SNPs showed sequence conservation with a protein that is involved in transposition to unrelated chromosomal sites. This finding strengthens the transposon theory that was suggested for $G c$ genes of wheat and related species by Tsujimoto and Tsunewaki [71], which was based on hybrid dysgenesis in Drosophila melanogaster, caused by mobile P elements. In fact, in both of the systems, the observed symptoms include sterility, lethality, mutations, and chromosome breakage; hence, also for the $4 \mathrm{~S}^{\text {sh }} \mathrm{L}$ Gc case, the two-loci theory, with the involvement of mobile element(s), appears as a likely hypothesis: the breaker element might be a transposon similar to the Drosophila P elements, and the inhibitor would be located close to the breaker in the sub-telomeric region $[69,70]$.

The one just described remains so far the best studied case of genes underlying SD phenotypes in wheat and related species. However, when considering that such genes are widely spread, if not omnipresent, in plants, in which they must have played a major evolutionary role in terms of karyotype diversification and speciation by sexual isolation, it seems reasonable to expect a variety of elements and mechanisms responsible for these phenotypes between and within species [36,55,65]. In this frame, epigenetic phenomena should also be contemplated. In fact, since Barbara McClintock's intuition that "species crosses are another potent source of genome modification that could yield TE activation" [72], a large body of evidence has demonstrated that the merging of parental species in hybrids and allopolyploids can lead to a "genomic shock", which triggers the dysregulation of normal cell functions and various forms of pertubations, almost invariably resulting in activation of previously silent transposable elements (TEs) [73-75]. Besides that in complete interspecific hybrids, epigenetic changes, particularly the alteration of DNA methylation patterns, have been observed in introgression lines of rice $[76,77]$ and wheat $[78,79]$ involving even sub-chromosomal amounts of alien chromatin. In some such contexts, sequences that were corresponding to TEs were shown to be the main target of altered DNA methylation [79].

Alteration in the pattern of allele/chromosome segregation is among the phenomena correlated to chromatin modifications, as clearly demonstrated in the Segregation Distorter $(S D)$ system of Drosophila [44]. In line with this, changes in the pattern of segregation distortion of parental alleles, besides that in the position of meiotic recombination, were found to be induced in an inter-subspecific cross of Oryza sativa L. by modification of inactive chromatin states [52]. As a whole, the available evidence suggests that the introduction of alien material into a recipient background can affect and/or induce a variety of SD phenotypes, not only causing new cis-trans genetic interactions (see the background-dependent effects above recalled), but also through epigenetic alterations. 
In this view, the disruption of the genetic and epigenetic makeup of an alien and/or recipient chromosome may imply the outbreak of SD phenomena not exhibited by the original structure(s). This may be the case for the pattern of segregation displayed by the bread wheat-Thinopyrum recombinant types described earlier (see $\S 3$ ), carrying $7 \mathrm{E}$ and $7 \mathrm{el}_{1}$ portions onto or in place of wheat chromosome 7D (Figure 3).

In contrast to the good fit $(>0.5)$ to the normal 1:2:1 segregation ratio that was detected in $F_{2}$ progeny from 7D-7E double monosomics with different backgrounds (Table 4), which confirms early observations on the absence of marked SD associated to the complete chromosome 7E [80], recombinant 7E chromosomes, partly substituted on their long (L) arm (7EL) by distal portions of $7 \mathrm{el}_{1} \mathrm{~L}$, displayed significantly deviated ratios. These were in favour of segregates that lacked the alien segment (HOM-), indicating a suicidal behaviour of gametes (not ascertained whether male or female or both) carrying an altered 7E, with the deviation being of considerable extent even for the R7-1 chromosome, in which the length of the "alien" $7 \mathrm{el}_{1} \mathrm{~L}$ segment is minimal (Figure 3). On the other hand, all of the recombinant chromosomes of the $\mathrm{T} 4$ type, i.e., carrying a $70 \%$ long $7 \mathrm{el}_{1} \mathrm{~L}$ segment with 7EL insertions of variable length (Figure 3), including some particularly amenable for breeding exploitation (see § 3), showed, irrespective of the background genotype, normal segregation, not differently from the original $\mathrm{T} 4$ segment (Table 4).

Table 4. Segregation ratios in $\mathrm{F}_{2}$ progenies from the cross of 7E/7el 1 recombinants and parental lines (T4 and the 7E(7D) substitution line), taken as control, with normal bread wheat cultivars (CS or Blasco). Maps of recombinant chromosomes are reported in Figure 3.

\begin{tabular}{|c|c|c|c|c|c|c|}
\hline \multirow{2}{*}{ Recomb. Genotype } & \multirow{2}{*}{ Chromosome Type } & \multicolumn{5}{|c|}{$F_{2}$ Segregation } \\
\hline & & HOM+ & HET & HOM- & $X^{2}$ 1:2:1 & $p$ Value $^{1}$ \\
\hline R69-9/CS & T4/distal 7EL & 3 & 4 & 3 & 0.36 & 0.83 \\
\hline R69-9/2*Blasco & & 8 & 8 & 8 & 2.67 & 0.26 \\
\hline R74-10/2*Blasco & $"$ & 21 & 32 & 15 & 1.29 & 0.52 \\
\hline R74-10/4*Blasco & & 10 & 21 & 5 & 3.18 & 0.20 \\
\hline R175-5/CS & $"$ & 14 & 16 & 6 & 4.00 & 0.14 \\
\hline R175-5/2*Blasco & & 6 & 8 & 10 & 4.00 & 0.14 \\
\hline R71-1/CS & $"$ & 8 & 20 & 8 & 0.44 & 0.80 \\
\hline R71-1/2*Blasco & & 4 & 4 & 5 & 2.07 & 0.36 \\
\hline R69-6/Blasco & " & 9 & 12 & 3 & 3.0 & 0.22 \\
\hline R7-1/Blasco & $7 \mathrm{E} /$ distal $_{7 \mathrm{el}_{1} \mathrm{~L}}$ & 7 & 27 & 26 & 12.63 & $0.002 * *$ \\
\hline R4-4/Blasco & " & 8 & 21 & 26 & 14.85 & $0.000 * * *$ \\
\hline R62-1/CS & $"$ & 8 & 15 & 17 & 6.55 & 0.04 * \\
\hline R74-9/Blasco & $"$ & 4 & 14 & 46 & 75.38 & $0.000^{* * *}$ \\
\hline R7-14/Blasco & $"$ & 6 & 20 & 21 & 10.61 & $0.005^{* *}$ \\
\hline \multicolumn{7}{|l|}{ Parental lines } \\
\hline T4 (Thatcher)/CS & & 7 & 17 & 5 & 1.14 & 0.57 \\
\hline \multicolumn{2}{|c|}{ T4 (Thatcher)/CS / / Blasco } & 6 & 10 & 8 & 1.00 & 0.61 \\
\hline \multicolumn{2}{|c|}{ 7E(7D) substit. (CS)/CS } & 9 & 14 & 10 & 0.82 & 0.66 \\
\hline \multicolumn{2}{|c|}{ 7E(7D) substit. (CS)/Blasco } & 11 & 14 & 10 & 1.33 & 0.51 \\
\hline
\end{tabular}

For both the 7D-7el $1 / 7 \mathrm{E}$ (Table 4 ) and the $7 \mathrm{D}-7 \mathrm{el}_{1} / 7 \mathrm{el}_{2}$ (Table 3) recombinant types showing abnormal segregation, no appreciable alteration of plant morphology, seed set, and seed development was observed among different segregates (carriers or non-carriers of the recombinant chromosomes), and in comparison with control lines. Thus, no limitation to their possible utilization in breeding is caused by the $S d / G c$ factors they harbour. By contrast, $G c$ genes of some Aegilops species were found to also induce chromosome breakage in zygotic cells, often resulting in a varying degree of sterility and/or seed shrivelling (reviewed in [54]). However, these effects seem to be dependent on several factors, including the degree of "strength" and penetrance of the particular Gc gene, the type of 
gamete lacking the $G c$ gene(s), as well as the background genotype, as above mentioned for the overall SD phenotype. In cases where the presence of Gc genes, either linked to the target alien genes [81], or present in the initial hybrid genotype [82], did show undesirable effects on plant fertility, strategies have been adopted to overcome these effects, in one instance breaking the linkage with the desirable genes through ph1b-induced homoeologous recombination [81], in the other making use in the transfer scheme of an "anti-gametocidal" wheat mutant, whose mutated, hence ineffective, Gc locus [83], replaced the active one [82].

\section{The Way Forward}

To thwart the impoverishment of crop genetic base, resulting from domestication and recurrent selection in the course of the breeding process, the exploitation of genetic variation from even distant relatives of crop species has since long attracted considerable interest. In recent years, there has been a growing consensus about an important role that crop wild relatives (CWRs) can play in crop improvement. CWRs are more and more looked at as the nexus between food security, climate change adaptation, and biodiversity conservation issues [84]. This consciousness, coupled with the availability of a wide array of appropriate characterization and selection tools from fast developing fields of molecular genetics, cytogenetics, and genomics, has given a boost to effective strategies for the exploitation of the enormous, still unlocked potential of CWRs. One such strategy, recently called 'introgressiomics' [85], consists of a whole-genome introgression approach, that is transfer of chromosome segments from the entire genome of a given donor (mostly wild) species into the crop species background, irrespective of any traits that the wild relative might carry. The "step change" in this otherwise long-standing procedure of creation of interspecific $\mathrm{F}_{1}$ hybrids and derived amphidiploids or backcross progenies, is application of high-throughput screening technology to detect and characterize the obtained introgressions, as well as of efficient phenotyping to maximize exploitation of their potential. This would enable linking the recombinant genotypes to a variety of agronomically important target traits, of current, but also foreseen and unforeseen value, in line with a pre-emptive breeding perspective [85]. A recent successful example of this initially un-focused generation of genetic diversity accompanied by high-throughput genotyping involves wheat and one of its wild relatives, namely Amblyopyrum muticum (syn. Aegilops mutica) [86]. A high number of genome-wide, segmental Am. muticum introgressions into wheat could be detected by using a subset of a previously developed array of single nucleotide polymorphism (SNP) markers (SNPs), showing polymorphism between ten wild wheat relatives and wheat genotypes [87].

On the other hand, if specific target traits are identified, and so is the chromosomal or even sub-chromosomal location of the genes underlying them, a focused strategy can be successfully adopted to incorporate the smallest possible alien segments containing them into the crop genotype. In this, multiple chromosomal segments deriving from different alien sources and bearing different genes/QTL can then be pyramided, either on different recipient chromosomes, or stacked in a single, complex portion, as in the wheat-alien recombinant lines described above (see $\S 2$ and 3). Also, in the latter cases, the characterization and selection phases were helped by the use of appropriate analytical tools.

In all of the cases, the common objective of any interspecific, breeding-addressed transfer strategy is to exploit at best the alien donor trait(s), while minimizing possible linkage drag, which in principle represents a significant deterrent to using wild species in many crop improvement programs. To achieve this, a deeper knowledge of the alien genetic material, as well as the availability of an array of different transfer products for a given project objective, are essential pre-requisites. For instance, in the recombinant chromosomes in which alleles for various traits originating from different Thinopyrum species have been combined into bread wheat (Figure 3), knowledge of the differential effect of grain pigment content ascribable to the Th. elongatum and Th. ponticum Psy1 alleles [43] has been critical for the choice of the best candidate genotype for bread wheat or durum wheat improvement (see $\S 3$ ). On the other hand, unexpected outcomes may result from the introgression of alien genetic material 
into a cultivated background. Effects that are not detected in the donor species, but may become manifested when its genome, or a portion of it, is inserted in the new, nuclear or chromosomal, "environment", include the SD/Gc phenotypes above described (see $\S 4$ ), and also positive effects on yield, as those conferred by Th. ponticum genes/QTL present in $7 \mathrm{el}_{1} \mathrm{~L}$ segments incorporated into the bread wheat translocation line $\mathrm{T} 4$ or various durum wheat recombinant lines $([29,30]$ and references therein). Indeed, even Gc genes may have positive effects in a breeding perspective. On one hand, the preferential transmission of chromosomes with a gametocidal locus (Gc chromosomes), at least for those Gc genes with "mild" or no detrimental effects on the plant phenotype (see $\S 4$ ), ensures maintenance through subsequent generations of traits naturally, or even on purpose (e.g., by a GM approach), linked to the Gc locus, avoiding the need for trait selection. On the other hand, in several instances the ability of $G c$ genes to cause chromosomal breakages has been exploited to induce translocations into wheat of chromosomal segments belonging to relatively distant relatives, which are recalcitrant to homoeologous pairing promoting systems ([51,55,70] and references therein).

It seems thus clear that a comprehensive evaluation of the materials under study, including efficient genotyping and phenotyping, offers good promise for the practical use of alien genetic material, and of CWRs in particular. As suggested for the "introgressiomics" approach [85], any technology-assisted chromosome engineering of a crop genome with alien introgressions may well fit the definition that is given to 'new plant breeding techniques', such as cisgenesis and genome editing $[88,89]$. Both of the approaches allow to overcome interspecific barriers and eliminate CWRs-associated linkage drag; however, in contrast to the randomness of the insertion using a cisgenic gene delivery, genome editing techniques allow to edit, delete, replace, or insert, in targeted sites, specific genomic sequences of interest, even addressing multiple genes simultaneously $[90,91]$. Thus, genome editing, particularly through the highly versatile CRISP/Cas approach or additional future technological refinements, is predicted to revolutionize plant breeding. However, both cisgenesis and genome editing require knowledge of the genetic basis of the trait(s) of interest, still lacking or incomplete for several species of agricultural importance, particularly the CWRs. Moreover, legal uncertainty and the still widespread consumer concern about these technologies restrict their current usefulness. A wise reasoning would probably be that, while awaiting for wider genomic information on at least the most relevant species and accessions of CWRs to come, and legal/social bottlenecks for the implementation of high-precision biotechnological approaches, particularly genome editing, into the breeding pipeline to be overcome, the available "smart" strategies of chromosome engineering, whether being focused or initially unfocused, should be taken advantage of and valorized. As the examples that are reported in the present review hopefully contribute to demonstrate, they prove to be "ripe" for an effective "rewilding" [92] of our main crops, with wheat being one of the most significant, hence targeted, species. To this aim, investments in pre-breeding programs and human capacity development are highly recommended [84]. The latter issue is particularly addressed to counter the largely reported decline in available expertise in certain fields, including cytogenetics, botany, and taxonomy, which could effectively complement skill in recent technologies in harnessing at our best the treasure contained in CWRs. No doubt, such a holistic approach offers the highest potential for developing new generations of crops, with enhanced capacity and plasticity to perform well in changing and challenging environmental, agricultural, and societal scenarios.

Acknowledgments: Financial support from Lazio region-FILAS project "MIGLIORA" is gratefully acknowledged.

Author Contributions: Ljiljana Kuzmanović, Paola Forte, Alessia Cuccurullo and Alessandra Bitti performed the molecular marker-assisted selection and GISH analyses of the various wheat-alien recombinant lines; Roberto Ruggeri and Francesco Rossini were responsible for field tests; Ljiljana Kuzmanović, Roberto Ruggeri and Francesco Rossini performed the phenotyping of yield-related traits and analyzed the data; Ljiljana Kuzmanović, Roberto Ruggeri and Francesco Rossini contributed to the layout and editing of the manuscript; Carla Ceoloni coordinated the research and wrote the manuscript.

Conflicts of Interest: The authors declare no conflict of interest. 


\section{References}

1. Statista-The Statistical Portal: Global Grain Acreage by Type-2011/12 to 2016/17. Available online: https: / / www.statista.com/statistics/272536/acreage-of-grain-worldwide-by-type/ (accessed on 30 July 2017).

2. Giorgi, B.; Porfiri, O. (Eds.) The Varieties of Strampelli: A Milestone in Wheat Breeding in Italy and in the World. In Proceedings of the Special Session of the $41^{\text {st }}$ Annual Congress of the Italian Society of Agricultural Genetics (SIGA), Abbadia di Fiastra, Tolentino, Italy, 26 September 1997; Tipografia San Giuseppe: Pollenza, Italy, 1998; pp. 1-63, (In Italian with English Abstracts).

3. Borlaug, N.E. Sixty-two years of fighting hunger: Personal recollections. Euphytica 2007, 157, $287-297$. [CrossRef]

4. Calderini, D.F.; Slafer, G.A. Changes in yield and yield stability in wheat during the 20th century. Field Crops Res. 1998, 57, 335-347. [CrossRef]

5. De Vita, P.; Nicosia, O.L.D.; Nigro, F.; Platani, C.; Riefolo, C.; Di Fonzo, N.; Cattivelli, L. Breeding progress in morpho-physiological, agronomical and qualitative traits of durum wheat cultivars released in Italy during the 20th century. Eur. J. Agron. 2007, 26, 39-53. [CrossRef]

6. Fischer, T.; Byerlee, D.; Edmeades, G. Crop Yields and Global Food Security: Will Yield Increase Continue to Feed the World? ACIAR Monograph No. 158; Australian Centre for International Agricultural Research: Canberra, Australia, 2014; p. xxii + 634 .

7. Lobell, D.B.; Gourdji, S.M. The influence of climate change on global crop productivity. Plant Physiol. 2012, 160, 1686-1697. [CrossRef] [PubMed]

8. Tilman, D.; Balzer, C.; Hill, J.; Befort, B.L. Global food demand and the sustainable intensification of agriculture. Proc. Natl. Acad. Sci. USA 2011, 108, 20260-20264. [CrossRef] [PubMed]

9. Hawkesford, M.; Araus, J.; Park, R.; Calderini, D.; Miralles, D.; Shen, T.; Zhang, J.; Parry, M.A.J. Prospects of doubling global wheat yields. Food Energy Secur. 2013, 2, 34-48. [CrossRef]

10. Mujeeb-Kazi, A.; Kazi, A.G.; Dundas, I.; Rasheed, A.; Ogbonnaya, F.; Kishii, M.; Bonnett, D.; Wang, R.R.-C.; $\mathrm{Xu}, \mathrm{S}$; Chen, P.; et al. Genetic diversity for wheat improvement as a conduit to food security. In Advances in Agronomy; Sparks, D.L., Ed.; Academic Press: Burlington, NI, USA, 2013; Volume 122, pp. 179-257.

11. Molnár-Láng, M.; Ceoloni, C.; Doležel, J. (Eds.) Alien Introgression in Wheat-Cytogenetics, Molecular Biology, and Genomics; Springer: Cham, Switzerland, 2015; pp. 1-385. [CrossRef]

12. Sears, E.R. Transfer of alien genetic material to wheat. In Wheat Science-Today and Tomorrow; Evans, L.T., Peacock, W.J., Eds.; Cambridge University Press: Cambridge, UK, 1981; pp. 75-89.

13. Naranjo, T.; Benavente, E. The mode and regulation of chromosome pairing in wheat-alien hybrids (Ph genes, an updated view). In Alien Introgression in Wheat-Cytogenetics, Molecular Biology, and Genomics; Molnár-Láng, M., Ceoloni, C., Doležel, J., Eds.; Springer: Cham, Switzerland, 2015; pp. 133-162.

14. Ceoloni, C.; Biagetti, M.; Ciaffi, M.; Forte, P.; Pasquini, M. Wheat chromosome engineering at the $4 \mathrm{x}$ level: The potential of different alien gene transfers into durum wheat. Euphytica 1996, 89, 87-97. [CrossRef]

15. Ceoloni, C.; Jauhar, P.P. Chromosome engineering of the durum wheat genome: Strategies and applications of potential breeding value. In Genetic Resources, Chromosome Engineering, and Crop Improvement: Cereals; Singh, R.J., Jauhar, P.P., Eds.; CRC Press: Boca Raton, FL, USA, 2006; pp. $27-59$.

16. Qi, L.; Friebe, B.; Zhang, P.; Gill, B.S. Homoeologous recombination, chromosome engineering and crop improvement. Chromosome Res. 2007, 15, 3-19. [CrossRef] [PubMed]

17. Ayala-Navarrete, L.; Mechanicos, A.A.; Gibson, J.M.; Singh, D.; Bariana, H.S.; Fletcher, J.; Shorter, S.; Larkin, P.J. The Pontin series of recombinant alien translocations in bread wheat: Single translocations integrating combinations of Bdv2, Lr19 and Sr25 disease-resistance genes from Thinopyrum intermedium and Th. ponticum. Theor. Appl. Genet. 2013, 126, 2467-2475. [CrossRef] [PubMed]

18. Niu, Z.; Klindworth, D.L.; Friesen, T.L.; Chao, S.; Ohm, J.B.; Xu, S.S. Development and characterization of wheat lines carrying stem rust resistance gene Sr43 derived from Thinopyrum ponticum. Theor. Appl. Genet. 2014, 127, 969-980. [CrossRef] [PubMed]

19. Danilova, T.V.; Zhang, G.; Liu, W.; Friebe, B.; Gill, B.S. Homoeologous recombination-based transfer and molecular cytogenetic mapping of a wheat streak mosaic virus and Triticum mosaic virus resistance gene Wsm3 from Thinopyrum intermedium. Theor. Appl. Genet. 2017, 130, 549-555. [CrossRef] [PubMed] 
20. Liu, W.; Koo, D.-H.; Xia, Q.; Li, C.; Bai, F.; Song, Y.; Friebe, B.; Gill, B.S. Homoeologous recombination-based transfer and molecular cytogenetic mapping of powdery mildew-resistant gene Pm57 from Aegilops searsii into wheat. Theor. Appl. Genet. 2017, 130, 841-848. [CrossRef] [PubMed]

21. Ceoloni, C.; Pasquini, M.; Simeone, R. The cytogenetic contribution to the analysis and manipulation of the durum wheat genome. In Durum Wheat Breeding: Current Approaches and Future Strategies; Royo, C., Nachit, M.N., Di Fonzo, N., Araus, J.L., Pfeiffer, W.H., Slafer, G.A., Eds.; Haworth Press: New York, NY, USA, 2005; pp. 165-196.

22. Ceoloni, C.; Forte, P.; Gennaro, A.; Micali, S.; Carozza, R.; Bitti, A. Recent developments in durum wheat chromosome engineering. Cytogenet. Genome Res. 2005, 109, 328-344. [CrossRef] [PubMed]

23. Klindworth, D.L.; Niu, Z.; Chao, S.; Friesen, T.L.; Jin, Y.; Faris, J.D.; Cai, X.; Xu, S.S. Introgression and characterization of a goatgrass gene for a high level of resistance to Ug99 stem rust in tetraploid wheat. G3 Genes Genomes Genet. 2012, 2, 665-673. [CrossRef] [PubMed]

24. Han, C.; Zhang, P.; Ryan, P.R.; Rathjen, T.M.; Yan; Z.H.; Delhaize, E. Introgression of genes from bread wheat enhances the aluminium tolerance of durum wheat. Theor. Appl. Genet. 2016, 129, 729-739. [CrossRef] [PubMed]

25. Gennaro, A.; Forte, P.; Carozza, R.; Savo Sardaro, M.L.; Ferri, D.; Bitti, A.; Borrelli, G.M.; D’Egidio, M.G.; Ceoloni, C. Pyramiding different alien chromosome segments in durum wheat: Feasibility and breeding potential. Isr. J. Plant Sci. 2007, 55, 267-276. [CrossRef]

26. Gennaro, A.; Forte, P.; Panichi, D.; Lafiandra, D.; Pagnotta, M.A.; D’Egidio, M.G.; Ceoloni, C. Stacking small segments of the $1 \mathrm{D}$ chromosome of bread wheat containing major gluten quality genes into durum wheat: Transfer strategy and breeding prospects. Mol. Breed. 2012, 30, 149-167. [CrossRef]

27. Morris, C.F.; Simeone, M.N.; King, G.E.; Lafiandra, D. Transfer of soft kernel texture from Triticum aestivum to durum wheat, Triticum turgidum ssp. durum. Crop Sci. 2011, 51, 114-122. [CrossRef]

28. Gazza, L.; Sgrulletta, D.; Cammerata, A.; Gazzelloni, G.; Galassi, E.; Pogna, N. Breeding and quality of soft-textured durum wheat. In Proceedings of the International Symposium on Genetics and Breeding of Durum Wheat, Rome, Italy, 27-30 May 2013; Options Méditerranéennes, Séries A; No. 110. Porceddu, E., Damania, A.B., Qualset, C.O., Eds.; 2014; pp. 511-516.

29. Kuzmanović, L.; Gennaro, A.; Benedettelli, S.; Dodd, I.C.; Quarrie, S.A.; Ceoloni, C. Structural-functional dissection and characterization of yield-contributing traits originating from a group 7 chromosome of the wheatgrass species Thinopyrum ponticum after transfer into durum wheat. J. Exp. Bot. 2014, 65, 509-525. [CrossRef] [PubMed]

30. Kuzmanović, L.; Ruggeri, R.; Virili, M.E.; Rossini, F.; Ceoloni, C. Effects of Thinopyrum ponticum chromosome segments transferred into durum wheat on yield components and related morpho-physiological traits in Mediterranean rain-fed conditions. Field Crops Res. 2016, 186, 86-98. [CrossRef]

31. Ceoloni, C.; Margiotta, B.; Colaprico, G.; D'Egidio, M.G.; Carozza, R.; Lafiandra, D. Introgression of D-genome associated gluten protein genes into durum wheat. In Proceedings of the 10th International Wheat Genetics Symposium, Paestum, Italy, 1-6 September 2003; S.I.M.I: Rome, Italy, 2003; pp. 1320-1322.

32. Micali, S.; Forte, P.; Bitti, A.; D'Ovidio, R.; Ceoloni, C. Chromosome engineering as a tool for effectively introgressing multiple useful genes from alien Triticeae into durum wheat. In Proceedings of the 10th International Wheat Genetics Symposium, Paestum, Italy, 1-6 September 2003; pp. 896-898.

33. Gennaro, A.; Koebner, R.M.D.; Ceoloni, C. A candidate for Lr19, an exotic gene conditioning leaf rust resistance in wheat. Funct. Integr. Genom. 2009, 9, 325-334. [CrossRef] [PubMed]

34. Cenci, A.; D'Ovidio, R.; Tanzarella, O.A.; Ceoloni, C.; Porceddu, E. Identification of molecular markers linked to Pm13, an Aegilops longissima gene conferring resistance to powdery mildew of wheat. Theor. Appl. Genet. 1999, 98, 448-454. [CrossRef]

35. Klindworth, D.L.; Hareland, G.A.; Elias, E.M.; Xu, S.S. Attempted compensation for linkage drag affecting agronomic characteristics of durum wheat 1AS/1DL translocation lines. Crop Sci. 2013, 53, 422-429. [CrossRef]

36. Ceoloni, C.; Kuzmanović, L.; Gennaro, A.; Forte, P.; Giorgi, D.; Grossi, M.R.; Bitti, A. Genomes, chromosomes and genes of perennial Triticeae of the genus Thinopyrum: The value of their transfer into wheat for gains in cytogenomic knowledge and 'precision' breeding. In Advances in Genomics of Plant Genetic Resources; Tuberosa, R., Graner, A., Frison, E., Eds.; Springer: Dordrecht, The Netherlands, 2014; pp. 333-358. 
37. Ceoloni, C.; Kuzmanović, L.; Forte, P.; Virili, M.E.; Bitti, A. Wheat-perennial Triticeae introgressions: Major achievements and prospects. In Alien Introgression in Wheat-Cytogenetics, Molecular Biology, and Genomics; Molnár-Láng, M., Ceoloni, C., Doležel, J., Eds.; Springer: Cham, Switzerland, 2015; pp. 273-313.

38. Ayala-Navarrete, L.; Bariana, H.S.; Singh, R.P.; Gibson, J.M.; Mechanicos, A.A.; Larkin, P.J. Trigenomic chromosomes by recombination of Thinopyrum intermedium and Th. ponticum translocations in wheat. Theor. Appl. Genet. 2007, 116, 63-75. [CrossRef] [PubMed]

39. Shen, X.; Ohm, H. Molecular mapping of Thinopyrum-derived Fusarium head blight resistance in common wheat. Mol. Breed. 2007, 20, 131-140. [CrossRef]

40. Zhang, X.L.; Shen, X.R.; Hao, Y.F.; Cai, J.J.; Ohm, H.W.; Kong, L. A genetic map of Lophopyrum ponticum chromosome 7E, harboring resistance genes to Fusarium head blight and leaf rust. Theor. Appl. Genet. 2011, 122, 263-270. [CrossRef] [PubMed]

41. Forte, P.; Virili, M.E.; Kuzmanović, L.; Moscetti, I.; Gennaro, A.; D’Ovidio, R.; Ceoloni, C. A novel assembly of Thinopyrum ponticum genes into the durum wheat genome: Pyramiding Fusarium head blight resistance onto recombinant lines previously engineered for other beneficial traits from the same alien species. Mol. Breed. 2014, 34, 1701-1716. [CrossRef]

42. Guo, J.; Zhang, X.; Hou, Y.; Cai, J.; Shen, X.; Zhou, T.; Xu, H.; Ohm, H.W.; Wang, H.; Li, A.; et al. High-density mapping of the major FHB resistance gene $F h b 7$ derived from Thinopyrum ponticum and its pyramiding with Fhb1 by marker-assisted selection. Theor. Appl. Genet. 2015, 128, 2301-2316. [CrossRef] [PubMed]

43. Ceoloni, C.; Forte, P.; Kuzmanović, L.; Tundo, S.; Moscetti, I.; De Vita, P.; Virili, M.E.; D’Ovidio, R. Cytogenetic mapping of a major locus for resistance to Fusarium head blight and crown rot of wheat on Thinopyrum elongatum 7EL and its pyramiding with valuable genes from a Th. ponticum homoeologous arm onto bread wheat 7DL. Theor. Appl. Genet. 2017, 130, 2005-2024. [CrossRef] [PubMed]

44. Lyttle, T.W. Segregation distorters. Ann. Rev. Genet. 1991, 25, 511-557. [CrossRef] [PubMed]

45. Hurst, G.D.D.; Werren, J.H. The role of selfish genetic elements in eukaryotic evolution. Nat. Rev. Genet. 2001, 2, 597-606. [CrossRef] [PubMed]

46. Taylor, D.R.; Ingvarsson, P.K. Common features of segregation distortion in plants and animals. Genetica 2003, 117, 27-35. [CrossRef] [PubMed]

47. Liu, X.; Guo, L.; You, J.; Liu, X.; He, Y.; Yuan, J.; Liu, G.; Feng, Z. Progress of segregation distortion in genetic mapping of plants. Res. J. Agron. 2010, 4, 78-83. [CrossRef]

48. Burt, A.; Trivers, R. Selfish Genetic Elements. In Genes in Conflict-The Biology of Selfish Genetic Elements; Belknap Press: Cambridge, UK, 2006; pp. 1-18.

49. Li, C.; Bai, G.; Chao, S.; Wang, Z. A High-density SNP and SSR consensus map reveals segregation distortion regions in wheat. BioMed Res. Int. 2015, 2015, 830618. [CrossRef] [PubMed]

50. Seymour, D.K.; Chae, E.; Ariöz, B.I.; Koenig, D.; Weigel, D. The genetic architecture of recurrent segregation distortion in Arabidopsis thaliana. bioRxiv 2017. [CrossRef]

51. Endo, T.R. The gametocidal chromosome as a tool for chromosome manipulation in wheat. Chromosome Res. 2007, 15, 67-75. [CrossRef] [PubMed]

52. Habu, Y.; Ando, T.; Ito, S.; Nagaki, K.; Kishimoto, N.; Taguchi-Shiobara, F.; Numa, H.; Yamaguchi, K.; Shigenobu, S.; Murata, M.; et al. Epigenomic modification in rice controls meiotic recombination and segregation distortion. Mol. Breed. 2015, 35, 103. [CrossRef]

53. Kwiatek, M.T.; Wisniewska, H.; Slusarkiewicz-Jarzina, A.; Majka, J.; Majka, M.; Belter, J.; Pudelska, H. Gametocidal factor transferred from Aegilops geniculata Roth can be adapted for large-scale chromosome manipulations in cereals. Front. Plant Sci. 2017, 8, 409. [CrossRef] [PubMed]

54. Tsujimoto, H. Gametocidal genes in wheat as the inducer of chromosome breakage. In Frontiers of Wheat Bioscience; Memorial Issue, Wheat Information Service No. 100; Tsunewaki, K., Ed.; Kihara Memorial Yokohama Foundation: Yokohama, Japan, 2005; pp. 33-48.

55. Endo, T.R. Gametocidal genes. In Alien Introgression in Wheat-Cytogenetics, Molecular Biology, and Genomics; Molnár-Láng, M., Ceoloni, C., Doležel, J., Eds.; Springer: Cham, Switzerland, 2015; pp. 121-131.

56. Knott, D.R. The transfer of genes for disease resistance from alien species to wheat by induced translocations. In Mutation Breeding for Disease Resistance; IAEA: Vienna, Austria, 1971; pp. 67-77.

57. McIntosh, R.A.; Dyck, P.L.; Green, G.J. Inheritance of leaf rust and stem rust resistance in wheat cultivars Agent and Agatha. Aust. J. Agric. Res. 1976, 28, 37-45. [CrossRef] 
58. Kibirige-Sebunya, I.; Knott, D.R. Transfer of stem rust resistance to wheat from an Agropyron chromosome having a gametocidal effect. Can. J. Genet. Cytol. 1983, 25, 215-221. [CrossRef]

59. Scoles, G.J.; Kibirige-Sebunya, I.N. Preferential abortion of gametes in wheat induced by an Agropyron chromosome. Can. J. Genet. Cytol. 1983, 25, 1-6. [CrossRef]

60. Marais, G.F. Genetic control of a response to the segregation distortion allele, $S d-1 d$, in the common wheat line 'Indis'. Euphytica 1992, 60, 89-95.

61. Prins, R.; Marais, G.F. A genetic study of the gametocidal effect of the $L r 19$ translocation of common wheat. S. Afr. J. Plant Soil 1999, 16, 10-14. [CrossRef]

62. Marais, G.F.; Marais, A.S.; Groenwald, J.Z. Evaluation and reduction of Lr19-149, a recombined form of the Lr19 translocation of wheat. Euphytica 2001, 121, 289-295. [CrossRef]

63. Groenwald, J.Z.; Fourie, M.; Marais, A.S.; Marais, G.F. Extention and use of a physical map of the Thinopyrum-derived Lr19 translocation. Theor. Appl. Genet. 2005, 112, 131-138. [CrossRef] [PubMed]

64. Cai, J.; Zhang, X.; Wang, B.; Yan, M.; Qi, Y.; Kong, L. A genetic analysis of segregation distortion revealed by molecular markers in Lophopyrum ponticum chromosome 7E. J. Genet. 2011, 90, 373-376. [CrossRef] [PubMed]

65. Endo, T.R. Gametocidal chromosomes and their induction of chromosome mutations in wheat. Jpn. J. Genet. 1990, 65, 135-152. [CrossRef]

66. Kong, L.; Anderson, J.M.; Ohm, H.W. Segregation distortion in common wheat of a segment of Thinopyrum intermedium chromosome 7E carrying Bdv3 and development of a Bdv3 marker. Plant Breed. 2008, 128, 591-597. [CrossRef]

67. Sun, Q.Y.; Breitbart, H.; Schatten, H. Role of the MAPK cascade in mammalian germ cells. Reprod. Fertil. Dev. 2000, 11, 443-450. [CrossRef]

68. Xu, J.; Zhang, S. Mitogen-activated protein kinase cascades in signaling plant growth and development. Trends Plant Sci. 2015, 20, 56-64. [CrossRef] [PubMed]

69. Knight, E.; Binnie, A.; Draeger, T.; Moscou, M.; Rey, M.-D.; Sucher, J.; Mehra, S.; King, I.; Moore, G. Mapping the 'breaker' element of the gametocidal locus proximal to a block of sub-telomeric heterochromatin on the long arm of chromosome $4 S^{\text {sh }}$ of Aegilops sharonensis. Theor. Appl. Genet. 2015, 128, 1049-1059. [CrossRef] [PubMed]

70. Grewal, S.; Gardiner, L-J.; Ndreca, B.; Knight, E.; Moore, G.; King, I.P.; King, J. Comparative mapping and targeted-capture sequencing of the gametocidal loci in Aegilops sharonensis. Plant Genome 2017, 10. [CrossRef] [PubMed]

71. Tsujimoto, H.; Tsunewaki, K. Hybrid dysgenesis in common wheat caused by gametocidal genes. Jpn. J. Genet. 1985, 60, 565-578. [CrossRef]

72. McClintock, B. The significance of responses of the genome to challenge. Science 1984, 226, $792-801$. [CrossRef] [PubMed]

73. Shaked, H.; Kashkush, K.; Ozkan, H.; Feldman, M.; Levy, A.A. Sequence elimination and cytosine methylation are rapid and reproducible responses of the genome to wide hybridization and allopolyploidy in wheat. Plant Cell 2001, 13, 1749-1759. [CrossRef] [PubMed]

74. Feldman, M.; Levy, A.A. Genome evolution in allopolyploid wheat-A revolutionary reprogramming followed by gradual changes. J. Genet. Genom. 2009, 36, 511-518. [CrossRef]

75. Levy, A.A. Transposons in plant speciation. In Plant Transposons and Genome Dynamics in Evolution, 1st ed.; Fedoroff, N.V., Ed.; John Wiley \& Sons, Inc.: Hoboken, NJ, USA, 2013; pp. 165-179.

76. Liu, Z.; Wang, Y.; Shen, Y.; Guo, W.; Hao, S.; Liu, B. Extensive alterations in DNA methylation and transcription in rice caused by introgression from Zizania latifolia. Plant Mol. Biol. 2004, 54, 571-582. [CrossRef] [PubMed]

77. Dong, Z.Y.; Wang, Y.M.; Zhang, Z.J.; Shen, Y.; Lin, X.Y.; Ou, X.F.; Han, F.P.; Liu, B. Extent and pattern of DNA methylation alteration in rice lines derived from introgressive hybridization of rice and Zizania latifolia Griseb. Theor. Appl. Genet. 2006, 113, 196-205. [CrossRef] [PubMed]

78. Zhang, Y.; Liu, Z.H.; Liu, C.; Yang, Z.J.; Deng, K.J.; Peng, J.H.; Zhou, J.P.; Li, G.R.; Tang, Z.X.; Ren, Z.L. Analysis of DNA methylation variation in wheat genetic background after alien chromatin introduction based on methylation-sensitive amplification polymorphism. Sci. Bull. 2008, 53, 58-69. [CrossRef]

79. Fu, S.; Sun, C.; Yang, M.; Fei, Y.; Tan, F.; Yan, B.; Ren, Z.; Tang, Z. Genetic and epigenetic variation induced by wheat-rye $2 \mathrm{R}$ and 5R monosomic addition lines. PLoS ONE 2013, 8, e54057. [CrossRef] [PubMed] 
80. Dvorak, J. Homoeology between Agropyron elongatum chromosomes and Triticum aestivum chromosomes. Can. J. Genet. Cytol. 1980, 22, 237-259. [CrossRef]

81. Marais, G.F.; Bekker, T.A.; Eksteen, A.; McCallum, B.; Fetch, T.; Marais, A.S. Attempts to remove gametocidal genes co-transferred to common wheat with rust resistance from Aegilops speltoides. Euphytica 2010, 171, 71-85. [CrossRef]

82. Millet, E.; Manisterski, J.; Ben-Yehuda, P.; Distelfeld, A.; Deek, J.; Wan, A.; Chen, X.; Steffenson, B.J. Introgression of leaf rust and stripe rust resistance from Sharon goatgrass (Aegilops sharonensis Eig) into bread wheat (Triticum aestivum L.). Genome 2014, 57, 309-316. [CrossRef] [PubMed]

83. Friebe, B.; Zhang, P.; Nasuda, S.; Gill, B.S. Characterization of a knockout mutation at the Gc2 locus in wheat. Chromosoma 2003, 111, 509-517. [CrossRef] [PubMed]

84. Dempewolf, H.; Baute, G.; Anderson, J.; Kilian, B.; Smith, C.; Guarino, L. Past and future use of wild relatives in crop breeding. Crop Sci. 2017, 57, 1070-1082. [CrossRef]

85. Prohens, J.; Gramazio, P.; Plazas, M.; Dempewolf, H.; Kilian, B.; Díez, M.J.; Fita, A.; Herraiz, F.J.; Rodríguez-Burruezo, A.; Soler, S.; et al. Introgressiomics: A new approach for using crop wild relatives in breeding for adaptation to climate change. Euphytica 2017, 213, 158. [CrossRef]

86. King, J.; Grewal, S.; Yang, C.; Hubbart, S.; Scholefield, D.; Ashling, S.; Edwards, K.J.; Allen, A.M.; Burridge, A.; Bloor, C.; et al. A step change in the transfer of interspecific variation into wheat from Amblyopyrum muticum. Plant Biotechnol. J. 2017, 15, 217-226. [CrossRef] [PubMed]

87. Winfield, M.O.; Allen, A.M.; Burridge, A.J.; Barker, G.L.A.; Benbow, H.R.; Wilkinson, P.A.; Coghill, J.; Waterfall, C.; Davassi, A.; Scopes, G.; et al. High-density SNP genotyping array for hexaploid wheat and its secondary and tertiary gene pool. Plant Biotechnol. J. 2015, 13, 733-742. [CrossRef] [PubMed]

88. Lusser, M.; Parisi, C.; Plan, D.; Rodríguez-Cerezo, E. New Plant Breeding Techniques: State-of-the-Art and Prospects for Commercial Development; Reference Report by the Joint Research Centre of the European Commission; Publications Office of the European Union: Luxembourg, 2011. [CrossRef]

89. Cardi, T. Cisgenesis and genome editing: Combining concepts and efforts for a smarter use of genetic resources in crop breeding. Plant Breed. 2016, 135, 139-147. [CrossRef]

90. Lowder, L.G.; Zhang, D.; Baltes, N.J.; Paul, J.W.; Tang, X.; Zheng, X.; Voytas, D.F.; Hsieh, T.F.; Zhang, Y.; Qi, Y. A CRISPR/Cas9 toolbox for multiplexed plant genome editing and transcriptional regulation. Plant Physiol. 2015, 169, 971-985. [CrossRef] [PubMed]

91. Ma, X.; Zhang, Q.; Zhu, Q.; Liu, W.; Chen, Y.; Qiu, R.; Wang, B.; Yang, Z.; Li, H.; Lin, Y.; et al. A robust CRISPR/Cas9 system for convenient, high-efficiency multiplex genome editing in monocot and dicot plants. Mol. Plant 2015, 8, 1274-1284. [CrossRef] [PubMed]

92. Palmgren, M.G.; Edenbrandt, A.K.; Vedel, S.E.; Andersen, M.M.; Landes, X.; Osterberg, J.T.; Falhof, J.; Olsen, L.I.; Christensen, S.B.; Sandoe, P.; et al. Are we ready for back-to-nature crop breeding? Trends Plant Sci. 2015, 20, 155-164. [CrossRef] [PubMed]

(C) 2017 by the authors. Licensee MDPI, Basel, Switzerland. This article is an open access article distributed under the terms and conditions of the Creative Commons Attribution (CC BY) license (http:/ / creativecommons.org/licenses/by/4.0/). 